1. MBBS, FCPS

Assistant Professor of Medicine

Dow University Hospital

OJHA Campus Karachi

2. MBBS, FCPS

Assistant Professor of Medicine Dow University Hospital

OJHA Campus Karachi

3. MBBS, FCPS

Assistant Professor of Medicine

Dow University Hospital

OJHA Campus Karachi

4. MBBS, FCPS

Assistant Professor of Medicine

Dow University Hospital Karachi

Correspondence Address:

Dr. Ahsan Mobin

Assistant Professor of Medicine

Address: A-4, Block-8,

Azizabad, F.B Area, Karachi.

drahsanmobin@gmail.com

Article received on:

14/12/2015

Accepted for publication:

05/03/2016

Received after proof reading:

$12 / 04 / 2016$

\section{VACCINATED HEMODIALYSIS PATIENTS; \\ THE STATUS OF IMMUNITY AGAINST THE HEPATITIS B VIRUS, AT A TERTIARY CARE HOSPITAL}

\section{Dr. Ahsan Mobin', Dr. Fawed Qureshi², Dr. Muhammad Umar Khan ${ }^{3}$, Dr. Rakhshinda Jabeen ${ }^{4}$}

ABSTRACT... Objectives: Determine the status of immunity against the hepatitis $B$ virus among vaccinated hemodialysis patients at a tertiary care hospital. Study Design: Cross sectional study. Place and Duration of Study: All medical wards of Civil Hospital and Ojha campus, Dow University of Health Sciences, Karachi, Pakistan from May 2013 to January 2015. Methodology: Patients with chronic kidney disease on hemodialysis attending out-patient department were enrolled. Patients with either gender and aged 18-70 years, who give consent for participation, who are on HD for more than 9 months with a proven diagnosis of ESRD who have received a complete course of 4 doses of hepatitis B vaccination atleast 2 months back were included in this study. Non-consenting patients, present/past history of viral hepatitis, patients who were hepatitis B surface antigen $(\mathrm{HBsAg})$ positive, patients on immunosuppressive agents, pregnant patients were excluded from this study. Results: Out of the 103 patients, 69 (67\%) males and 34 (33\%) females with mean age of study population was $51.1 \pm 14.3$ years (17 to 70 years), mean duration post vaccination was $7.6 \pm 0.9$ months (6 to 9 months), mean anti HBs antibody level was $184.6 \pm 293.4$ (level rang 0 to 1000) and mean hemodialysis duration was $26.4 \pm 12$ months (10 to 50 month). Out of 37 non-responders 28 (75.7\%) had twice weekly schedule of hemodialysis and 09 (24.3\%) had thrice weekly schedule of hemodialysis, out of 19 weak responders 13 (68.4\%) had twice weekly schedule of hemodialysis and $06(31.6 \%)$ had thrice weekly schedule of hemodialysis and out of 47 high responders $29(61.7 \%)$ had twice weekly schedule of hemodialysis and 18 (38.3\%) had thrice weekly schedule of hemodialysis $(p=0.395)$. Conclusion: Excellent response of $\mathrm{HbsAg} \mathrm{B}$ vaccination for those patients, undergo dialysis procedure that is not associated with age, systemic inflammation or nutritional. Effective dialysis procedure associated with excellent response to the vaccine hepatitis $B$.

Key words: Hemodialysis, Hepatitis B, Immunity, Vaccination.

Article Citation: Mobin A, Qureshi F, Khan MU, Jabeen R. Vaccinated hemodialysis patients; the status of immunity against the hepatitis b virus, at a tertiary care hospital. Professional Med J 2016;23(4):396-400. DOI: 10.17957/TPMJ/16.3149

\section{INTRODUCTION}

Worldwide is a significant health problem occurred due to consequences of Hepatitis B virus (HBV) are chronic liver disease, cirrhosis, and hepatocellular carcinoma. Approximately 350 million chronic carriers worldwide are the main reservoir infection. ${ }^{1,2}$ With accessibility of vaccine HBV since 1982, a decline was reported in the incidence of HBV infection and morbidity and mortality. The immune to HBV vaccine assessed by measuring the levels of antibodies after 6 to 8 weeks after completion of the 3 doses. Hepatitis B surface of the body is greater than $10 \mathrm{mIU} / \mathrm{ml}$ is considered to be protective. ${ }^{3}$

Patients on hemodialysis (HD) more exposure for hepatitis B virus (HBV). Sources of HIV in the blood product transfusions, infection from the dialysis machines and other sources of environmental diseases. Patients with Chronic uremic, although dialysis or not, have a reduced immune to hepatitis B vaccine. ${ }^{4}$ Although vaccination of hepatitis $B$ virus (HBV) in healthy subjects resulted in a seroconversion rate of $90 \%$ to $100 \%$ for patients with end-stage renal disease have reduced responses to HBV vaccination with sufficient surface anti-hepatitis B (anti-HBs) unaffected by the amount of from $50 \%$ to $60 \%{ }^{5}$

Several methods have been tried to improve the immune seroconversion including adding additional capacity of inoculum injection four 
lines and doubling the dose of the vaccine at / $40 \mathrm{mcg}$ dose. One study reported a $80 \%$ seroconversion by this route. A. Ramezani, et al. their study found that after the initial inoculation, $87 \%$ of patients developed anti-hbs levels above $10 \mathrm{IU} / \mathrm{I}$. $27.8 \%$ and $59.2 \%$ of them have a weak high responders respectively. $13 \%$ of patients were non-responders. ${ }^{6}$

Although infection with HBV is a matter of large health care in community and hospital settings in Pakistan, the elements to evaluate the immune system in patients undergoing hemodialysis is not available. Given the $3-4 \%$ of the general spread of the virus and of the possibility of nosocomial transmission in the case of health care is important. ${ }^{7}$

Therefore, we designed this study at a one of the largest tertiary care centers of the country to evaluate the immune response among hemodialysis patients after completion of their vaccination schedule. ESRD is a immunocomromised state and these patients have a tendency of low immunity against hepatitis $B$ virus even on higher doses. At the end of this study we will be able to know the real scenario among the vaccinated hemodialysis patients and will be able to develop immunization protocol for Hepatitis B immunization of ESRD patients on haemodialysis.

\section{SUBJECTS AND METHODS}

This study was conducted in different medical wards of Civil Hospital and Ojha campus, Dow University of Health Sciences, Karachi, Pakistan from May 2013 to January 2015. Patients with chronic kidney disease on hemodialysis attending out-patient department were enrolled. Patients who received a double dose $(40 \mathrm{mcg})$ a recombinant hepatitis $B$ vaccine immunization four rows of the program as intramuscular injections in the deltoid muscle at 0, 1, 2 and 6 months were selected for hepatitis $B$ antibodies (anti HBS) tests. Measurement of hepatitis B surface of the body of the patient (anti-HBs) by ELISA after 1-2 months after the last injection. Subjects were divided into three groups according to the level of anti-HBs: Non-Responders ( $<10 \mathrm{IU}$ / I), responding patients (10 to $<100 \mathrm{IU} \mathrm{/} \mathrm{I)} \mathrm{and}$ high responders (equal to or more than $100 \mathrm{IU}$ / I). Patients with either gender and aged 18-70 years, who give consent for participation, who are on HD for more than 9 months with a proven diagnosis of ESRD who have received a complete course of 4 doses of hepatitis $B$ vaccination atleast 2 months back were included in this study. Non-consenting patients, present/past history of viral hepatitis, patients who were hepatitis $B$ surface antigen (HBsAg) positive, patients on immunosuppressive agents, pregnant patients were excluded from this study.

\section{RESULTS}

Out of the 103 patients, 69 (67\%) males and 34 (33\%) females with mean age of study population was $51.1 \pm 14.3$ years (17 to 70 years), mean duration post vaccination was $7.6 \pm 0.9$ months (6 to 9 months), mean anti HBs antibody level was $184.6 \pm 293.4$ (level rang 0 to 1000) and mean hemodialysis duration was $26.4 \pm 12$ months (10 to 50 month). Out of 69 males 42 (60.9\%) had twice weekly schedule of hemodialysis and 27 (39.1\%) had thrice weekly schedule of hemodialysis as compared to this out of 34 females $28(82.4 \%)$ had twice weekly schedule of hemodialysis and 06 (17.6\%) had thrice weekly schedule of hemodialysis. Analysis of anti HBS antibody status $37(35.9 \%)$ patients were nonresponders, 19 (18.4\%) were weak responders and 47 (45.6\%) were high responders.

On analysis of descriptive statistics among the gender it was observed that mean age of male patients was $52.6 \pm 14.5$ years, mean duration post vaccination of male patients was $7.5 \pm 0.88$ months, mean anti HBs antibody level of male patients was $162 \pm 260.6$ and mean hemodialysis duration of male patients was $28.2 \pm 13$ months as compared to these the mean age of female patients was $48.1 \pm 13.5$ years, mean duration post vaccination of female patients was $7.8 \pm$ 0.9 months, mean anti HBs antibody level of female patients was $230.5 \pm 350.4$ and mean hemodialysis duration of female patients was $22.7 \pm 9$ months (Table-l). 


\begin{tabular}{|c|c|c|c|c|}
\hline Gender & $\begin{array}{l}\text { Age Mean } \\
\text { (years) }\end{array}$ & $\begin{array}{l}\text { Duration post vaccination } \\
\text { (months) }\end{array}$ & Anti HBs antibody level & $\begin{array}{l}\text { Hemodialysis Duration } \\
\text { (months) }\end{array}$ \\
\hline Male & $52.55+14.5$ & $7.50+0.88$ & $162+260.6$ & $28.15+12.9$ \\
\hline$P$ value & 0.013 & 0.001 & 0.027 & 0.003 \\
\hline
\end{tabular}

Out of 37 non-responders $28(75.7 \%)$ had twice weekly schedule of hemodialysis and 09 (24.3\%) had thrice weekly schedule of hemodialysis, out of 19 weak responders $13(68.4 \%)$ had twice weekly schedule of hemodialysis and 06 (31.6\%) had thrice weekly schedule of hemodialysis and out of 47 high responders 29 (61.7\%) had twice weekly schedule of hemodialysis and 18 (38.3\%) had thrice weekly schedule of hemodialysis $(p=0.395)$ (Figure-1).

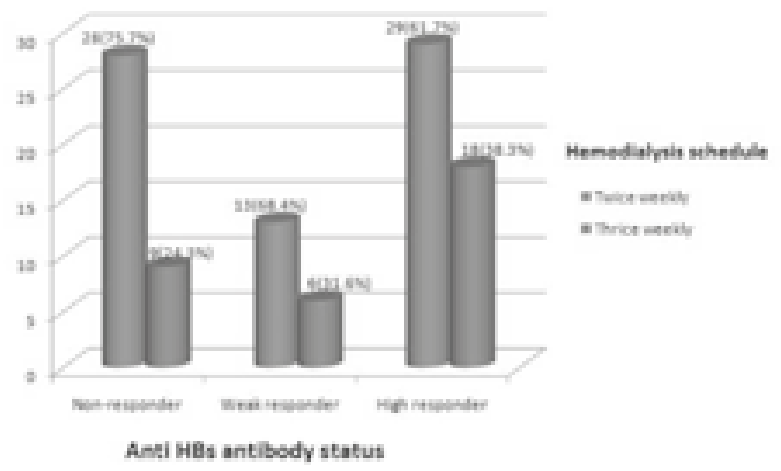

Figure-1. Analysis of Anti HBs Antibody Status among the Hemodialysis Schedule

\section{DISCUSSION}

Contact with Hepatitis B virus (HBV) is considered to be fairly high-risk among patients receiving treatment through dialysis. HBV in infected patients measures in at astonishingly elevated levels through blood and other contaminated bodily fluids. Handling of infected equipment and body surfaces of HBV patients assists in the transmission of HBV by dialysis technicians and healthcare professionals. In Pakistan, HBV is anescalatingconcern gaining serious attention regarding public health safety, while in numerous other countries of intermediate endemicity or high infection of HBV. ${ }^{8}$

Since its development in 1982, the Hepatitis-B vaccine is strongly recommended for all at risk patients undergoing dialysis treatment, however the seroconversion rates are rather decreased in the end-stage renal disease (ESRD) patient population. ${ }^{9,10}$ Between $73-76.7 \%$ of hemodialysis patients, seroconversion (anti-HBs > $10 \mathrm{IU} / 1$ ) occurred after three months of vaccine therapy, while an appropriate response (anti-HBs $>100$ IU/1) was noted in only $53.5 \%$ in one series. Further decreased response rates ranging between 47$58 \%$ to HBV vaccine have been observed after the fourth injection. ${ }^{11}$

Apart from the lower response rates, immunogenicity of the hepatitis-B vaccine is frequently short-lived, therefore requiring booster shots to receive continued protection against HBV. ${ }^{12}$ One study found that $41 \%$ of responders had no measurable levels of anti-HBs in the serum throughout a three-year follow-up. Factors such as malnutrition, uremia, oldage are correlated to poorer responses, along with an immunocompromised level of patients with chronic kidney disease. ${ }^{13}$

Elements linked with higher response rates to HBV vaccine include being below 40 years of age, well-nourished, and maintain tolerability to dialysis treatment. However, components such as the length of time of dialysis treatment, hemoglobin and parathyroid hormone level, along with the Hep C virus (HCV) infection didn't considerably impact antibody response to vaccine for hepatitis-B. Recent study demonstrated an elevated response to hepatitis-B vaccination among hemodialysis patient population. After full administration of the vaccination, $45.6 \%$ of patients revealed high antibody response (>100 IU/L). Past research studies have noted fluctuating hepatitis- $B$ vaccination response rates that ranged between $47-73 \%$ in hemodialysis 
patient populations. In comparison, satisfactory responses to the hepatitis- $B$ vaccine among dialysis patients have also been monitored in regions with endemicity (prevalence $2-8 \%$ ) of $\mathrm{HBV}$, an example includes Brazil, which came within reach of $89.5 \%$ in a study. ${ }^{13}$

Numerous research have shown when the hepatitis- $B$ vaccine is administered, even in high doses, it don't stimulate as notable a response in chronic renal failure patients as it does in non-hemodialysis patient population. There are various reasons behind the poor response of vaccination among hemodialysis patients. For example, uremia inhibits activation of and antigen-presentation to T-cells, and following antibody production. ${ }^{14}$

Fernandez et al ${ }^{15}$. Conducted a study which showed that malnutrition in the side of the target response to HBV in dialysis patients. 3-3.5 g/ dl albumin levels of $87.5 \%$ patients were nonresponders than when compared with $18.8 \%$ in group having serum albumin level between 4.5$5 \mathrm{~g} / \mathrm{dl}$. Another research study done by Kara et al ${ }^{16}$. noted that patients with serum albumin levels greater than $3.5 \mathrm{~g} / \mathrm{dl}$ had too great an antibody response to the hepatitis-B vaccine. 17 clinical trials demonstrated less response to the hepatitis- $B$ vaccination among elderly dialysis patients, which could be linked to the age-related variations in the immune system.

Physiological manifestations such as immune dysfunction, monocyte activation, and overproduction of pro-inflammatory cytokines are related with ESRD. Little previous research is available regarding the linked with chronic inflammation and immune response to the objectives of dialysis. This study was conducted and found no significant difference statistically in the CRP levels among responders as compared to non-responders. ${ }^{17}$

This result may be supported by the inconstant counter-production of interleukin-10 (IL-10), subsequently resulting in adequate $B$-cell function in uremic patients. In patients generating greater levels of IL-10, reduction in uremia is noted, as well as dialysis-induced chronic inflammation, along with improvements outcomes after vaccine application. ${ }^{18}$ Previous literature has mentioned the positive effect of effective dialysis on vaccination response to HBV in hemodialysis patients. One study conducted on patient's peritoneal dialysis immunize with the hepatitis- $B$ vaccine, the initial weekly Kt/V was 2.37 in responders, as compared to the 2.01 in the non-responders group. Since dialysis assists to replace impaired B7-2 (CD86) expression on monocytes in hemodialysis patients, effective dialysis may lead to a greater response. However, many other researchers have yet to confirm the advantageous effect of efficient dialysis on immune function. ${ }^{19}$ The entire patient population in this research study was reported to be positive for the anti-HCV antibody viral marker. ${ }^{20}$

\section{CONCLUSION}

Very good response hepatitis B vaccination for patients undergoing dialysis that is not correlated with age, systemic inflammation, or the state of nutrition. Dialysis succeeded associated with good response to the goal hepatitis $\mathrm{B}$. Future research to determine the most efficient format of vaccination in dialysis patients in our region. Copyright (C) 05 Mar, 2016.

\section{REFERENCES}

1. Rasoul A, El Bahnasy, Michael AA, Hendy OM, Ahmed $A R$. Hepatitis $B$ viral markers and vaccination status among health care providers in menoufia governorate. Egyp J Occupational Med 2010; 34(2):267-9.

2. Yacoub R, Ali R, Moukeh, G, Lahdo, A, Mouhammed Y, Nasser $M$. Hepatitis $B$ vaccination status and needle stick injuries among Health Care workers in Syria. J Global inf disea. 2010; 2(1):28-34.

3. Gunson RN, Sorald GL, Roggrndor FM, Nicholas H. Hepatitis $B$ virus and hepatitis $C$ virus infection in health care workers: guideline for prevention of transmission of HBV and HCV from HCW to patient. J Clin Virol 2003; 27:213-30.

4. Somi MH, Hajipour B. Improving Hepatitis B Vaccine Efficacy in End-Stage Renal Diseases Patients and Role of Adjuvants. ISRN Gastroenterol. 2012; 10-15. 
5. Filippelli M, Lionetti E, Gennaro A, Lanzafame A, Arrigo T, Salpietro C, La Rosa M, Leonardi S. Hepatitis B vaccine by intradermal route in non responder patients: An update. World J Gastroenterol 2014; 20(30): 10383-10394.

6. Ramezani A, Eslamifar A, Banifazl M, Ahmadi F, Maziar S, Razeghi E, et al. Efficacy and longterm immunogenicity of hepatitis $B$ vaccine in haemodialysis patients. Int J Clin Pract. 2009 Mar; 63(3):394-7.

7. Abbas Z, Jafri W, Shah SHA, Khokhar N, Zuberi SJ. Members of the Consensus panel. PSG consensus statement on management of hepatitis $B$ virus infection - 2003. J Pak Med Asso. 2004; 54:150-8.

8. Karkar A, Bouhaha BM, Dammang ML. Infection Control in Hemodialysis Units: A Quick Access to Essential Elements. Saudi J Kidney Dis Transpl 2014; 25(3):496-519.

9. Navarro JF, Teruel JL, Mateos ML. Antibody level after hepatitis $B$ vaccination in hemodialysis patients: influence of hepatitis $\mathbf{C}$ virus infection. Am J Nephrol. 1996;1 6(2):95-97.

10. Sit $D$, Esen $B$, Atay AE, Kayabaş $H$. Is hemodialysis a reason for unresponsiveness to hepatitis $B$ vaccine? Hepatitis $\mathrm{B}$ virus and dialysis therapy. World $\mathrm{J}$ Hepatol. 2015 Apr 18; 7(5): 761-768.

11. DaRoza G, Loewen A, Djurdjev 0. Stage of chronic kidney disease predicts Seroconversion after hepatitis B immunization: earier is better. Am J Kidney Dis. 2003; 42(6):1184-92.

12. Magnani G, Calzetti C, Campari M, et al. Immune response to hepatitis $B$ vaccine and duration of protection in a dialysis unit. Acta Biomed Ateneo
Parmense. 1987; 58(1-2):41-7.

13. Tele SA, Martins RM, Lopes CL. Immunogenicity of a recombinant hepatitis $B$ vaccine in hemodialysis patients and staff. Eur J Epidemiol. 2001; 17:145-9.

14. Nahar K, Jahan M, Nessa A, Tabassum S. Antibody responses after hepatitis $B$ vaccination among maintenance haemodialysis patients. Bangladesh Med Res Counc Bull 2011; 37: 88-91.

15. Fernandez E, Betriu MA, Gomez R. Response to the hepatitis $B$ virus vaccine in hemodialysis patients: influence of malnutrition and its importance as a risk factor for morbidity and mortality. Nephrol Dial Transplan. 1996; 11:1559-63.

16. Kara I, Yilmaz M, Suner A. The evaluation of immune responses that occur after HBV infection and HBV vaccination in hemodialysis patients. Vaccine 2004; 2:3963-67.

17. Fabrizi F, Dixit V, Bunnapradist S, Martin P. Metaanalysis: the dialysis mode and immunological response to hepatitis $B$ virus vaccine in dialysis population. Aliment Pharmacol. Ther 2006; 23: 11051112.

18. Girndt M, Sester U, Sester M. The intedeukin-1 0 promoter genotype determines clinical immune function in hemodialysis patients. Kidney tnt. 2001; 60 (6):2385-91.

19. Kovacic V, Sain M, Vukman V. Does efficient hemodialysis improve the response to hepatitis $B$ virus vaccination? Lijec Vjesn. 2004; 126(5-6):133-7.

20. Afifi A, Karim MA. Renal replacement therapy in Egypt: first annual report of the Egyptian society of nephrology. East Mediterr Health J. 1999; 5(5):1023-29.

\section{AUTHORSHIP AND CONTRIBUTION DECLARATION}

\begin{tabular}{|c|c|c|c|}
\hline Sr. \# & Author-s Full Name & Contribution to the paper & Author $=\mathbf{s}$ Signature \\
\hline 1 & Dr. Ahsan Mobin & $\begin{array}{l}\text { Conception and design, } \\
\text { Statistical expertise, } \\
\text { Critical revision of the } \\
\text { article for important } \\
\text { intellectual content }\end{array}$ & \\
\hline 2 & Dr. Fawed Qureshi & Data Collection & \\
\hline 3 & Dr. Muhammad Umar Khan & Drafting of the article & \\
\hline 4 & Dr. Rakhshinda Jabeen & Data Collection & Loustudint \\
\hline
\end{tabular}

